\title{
Teaching Dental Students to Interact with Survivors of Traumatic Events: Development of a Two-Day Module
}

\author{
Sheela Raja, PhD; Chelsea F. Rajagopalan, BA; Mariela Kruthoff, BA; \\ Alexandra Kuperschmidt; Priscilla Chang, DDS; Michelle Hoersch, MS
}

Abstract: Dentists are likely to treat patients who have experienced a wide range of traumatic life events, including child abuse and neglect, domestic violence, sexual assault, elder abuse, and exposure to combat. In order to effectively treat survivors of traumatic events, dentists must understand how these patients may present in oral health settings, the basic mandated reporting requirements related to abuse and neglect, and communication strategies to help engage trauma survivors in dental treatment. A traditional lecture-format educational module on trauma-informed care was developed and implemented for second-year dental students $(\mathrm{N}=92)$ at one U.S. dental school, after which a needs assessment was performed (all 92 students participated). This assessment then informed development of an enhanced module for the subsequent group of second-year dental students ( $\mathrm{N}=102)$ at the same school. The revised (final) module was more interactive in nature, expanded to multiple sessions, and included more discussion of mandated reporting and appropriate dentist-patient communication in relation to traumatic events. All 102 students participated in assessments of the revised module. Comparison of pre and post tests and needs assessments between the initial and final modules indicated that the extended, more interactive final module was more effective in meeting the educational objectives. Results showed that the final module increased the students' knowledge in the health-related manifestations of traumatic events and slightly improved their confidence levels in treating survivors of trauma. Dentists who are prepared to deliver traumainformed care may help individual patients feel more at ease and increase engagement in regular preventive care. Suggestions for future educational efforts in this area are discussed.

Dr. Raja is Assistant Professor and Director of Clinical Behavioral Sciences, Department of Pediatric Dentistry, College of Dentistry, University of Illinois at Chicago; Ms. Rajagopalan is a dental student, Rutgers School of Dental Medicine; Ms. Kruthoff is Research Assistant, University of Illinois at Chicago; Ms. Kuperschmidt is Research Assistant, University of Illinois at Chicago; Dr. Chang is Clinical Associate Professor, Department of Restorative Dentistry, College of Dentistry, University of Illinois at Chicago; and Ms. Hoersch is Women's Health Coordinator, Office on Women's Health, Chicago, IL. Direct correspondence to Dr. Sheela Raja, College of Dentistry, University of Illinois at Chicago, 801 S. Paulina St., M/C 850, Chicago, IL 60612; 312-413-0559; sraja1@uic.edu.

Keywords: dental education, professional attitudes, behavioral sciences, patient-centered care, patient-dentist relationships, patient-provider interaction, communication and interpersonal skills, domestic violence, abuse, interpersonal violence

Submitted for publication 4/28/14; accepted 6/30/14

$\mathrm{D}$ entists are likely to treat patients who have experienced a wide range of traumatic life events, including child abuse and/or neglect, domestic violence, sexual assault, elder abuse, and exposure to combat. ${ }^{1}$ The American Dental Association (ADA)'s Principles of Ethics and Code of Professional Conduct emphasize that dentists should be familiar with requirements for mandated reporting of abuse and neglect, as well the signs of abuse and how they present in an oral health setting. ${ }^{2}$ Significant educational efforts have focused on training oral health practitioners on mandated reporting; ${ }^{3-8}$ however, knowledge of mandated reporting is only one aspect of providing high-quality, patient-centered care. Health care professionals, including dentists, must be prepared to work skillfully and sensitively with patients who have experienced traumatic events.
In recent years, many disciplines have provided training in trauma-informed care for health care providers, ${ }^{9}$ but the creation of an interactive program specifically designed for dental students has not yet been reported. The basic definition of "traumainformed care" is when every part of service is "assessed and potentially modified to include a basic understanding of how trauma impacts the life of an individual seeking services." ${ }^{10}$ Trauma-informed care has been explored in relation to social service agencies for over a decade. ${ }^{11}$ That approach emphasizes the importance of screening patients for a history of trauma as appropriate, educating staff about the effects of trauma, making services as sensitive as possible, and encouraging patients to be involved in treatment decisions. 
Trauma victims may present to providers immediately following the trauma, or they may present later with a history of trauma. Providers need to be well versed in how to handle situations that involve immediate trauma and acute injury. ${ }^{12,13}$ In practice, dentists may observe, manage, and treat the physical signs and symptoms of a traumatic event, but may be hesitant or reluctant to consider domestic violence or sexual abuse as the etiology, even when there is immediate physical evidence that suggests a pattern of battering or invasion..$^{14}$ Dental students who received brief training on interpersonal violence have shown an improved understanding of the health-related aspects of violence after the educational experience. ${ }^{15,16}$ It is encouraging that education and knowledge appear to break down some of these barriers. In addition to acute injury, a history of traumatic events can also have long-term effects that are relevant to medical and dental care. Trauma survivors may engage in behaviors that help them "cope" with traumatic memories but have negative health consequences. ${ }^{17-19}$ For example, trauma survivors may smoke cigarettes, drink alcohol, or overeat to manage their emotional distress. Although these behaviors may provide short-term improvements in mood, they have long-term negative consequences on health, ${ }^{20-22}$ including oral health. ${ }^{23}$

Dentists may also treat patients who present with no visible signs of trauma and perform routine procedures that may elicit unfavorable memories and emotions of a previous trauma. Depending on the nature of the event, another long-term effect of trauma may be medical and dental anxiety that could affect dental treatment. For example, a history of childhood sexual trauma can influence how patients feel about dental care as adults. Common fears reported by victims are having to lie down for treatment, having objects put into their mouths, the dentist's hand(s) over the mouth/nose, not being able to breathe/swallow, perceived loss of control, and worry that the dentist may get angry. ${ }^{24}$ Patients who have experienced domestic violence, sexual assault, or combat may feel anxious and powerless because they cannot close their mouths or communicate during dental care. ${ }^{1}$ Thus, among survivors of trauma, dental phobia is more complex than fear of pain and needles. ${ }^{25}$ The supine position, being unable to talk, lack of control, and fear of being touched may be evoked in these survivors without the awareness of the dentist.

It is likely that dentists will interact with and treat survivors of traumatic events, such as after an acute injury or in a situation that involves mandated reporting. It is also probable that dentists will encounter survivors who experience chronic anxiety related to dental care or have ways of coping with traumatic memories (e.g., smoking, drinking, overeating) that are detrimental to oral health. The aim of this article is to describe how we developed and assessed an interactive educational module on trauma-informed care for dental students; we also explore how future educational efforts on this topic could be structured.

\section{Initial Module and Needs Assessment}

Because data were collected for educational purposes, this study was exempted by the University of Illinois at Chicago Institutional Review Board under protocol number 2014-0204. The initial module on trauma-informed care (TIC) in dentistry was a three-hour lecture session for second-year dental students at the University of Illinois at Chicago. Figure 1 provides an overview of the process by which we developed, refined, and evaluated this educational module. The objectives of the module were for students to learn how victims may present in the dental setting, the basic assessment and communication involved in mandated reporting of abuse and neglect, and behavioral techniques to help trauma survivors engage in dental treatment.

In the module, we began by reviewing the prevalence of traumatic events, including domestic violence, sexual abuse, elder abuse, child abuse, and combat. We described how these patients may present in dental settings both in the immediate aftermath of violence (e.g., with acute orofacial injuries, oral manifestations of sexually transmitted infections, pediatric dental neglect) and over the long term (e.g., dental anxiety, reluctance to engage in preventive care, using overeating and smoking as ways to cope with traumatic memories). We reviewed how dentists can assess for violence and under what circumstances they are mandated to report abuse or suspected abuse. Finally, we discussed ways that dentists could make traumatized patients feel more comfortable, including the use of informed consent, "tell-show-do" techniques, stop signals, empathic communication, observation of non-verbal indications of anxiety or discomfort, and providing appropriate referrals.

We were interested in determining whether this single three-hour lecture session would be sufficient to accomplish our learning objectives and, if not, how 

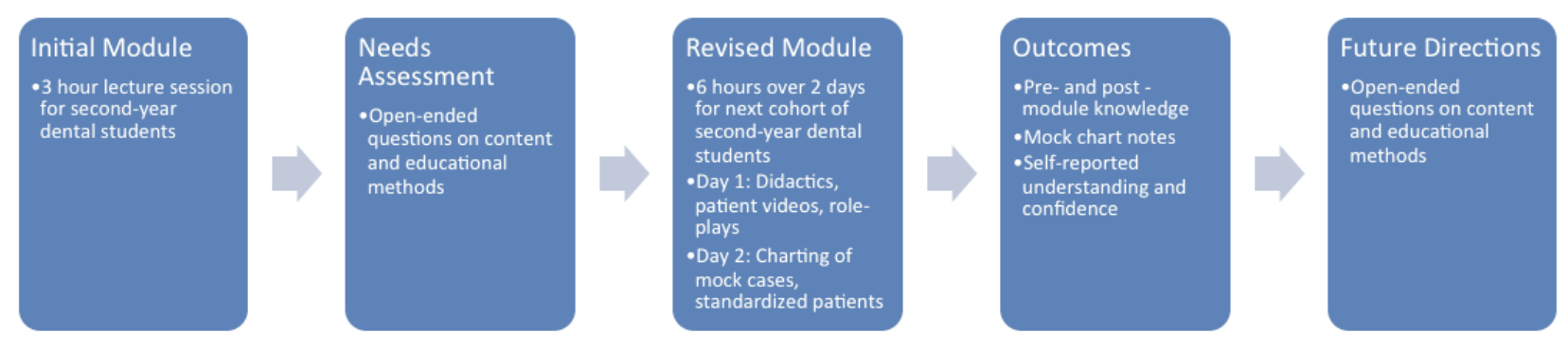

Figure 1. Process of assessment and revision of educational module on trauma-informed care

students would suggest improving their knowledge, skills, and application of TIC. After this session, we therefore asked the students to respond to openended questions to assess their needs and refine the module. We asked the students 1) what outstanding questions they had about working with survivors of traumatic events, 2) what additional topics they would like to see addressed in future sessions, and 3) what educational techniques they thought would be most helpful for them to feel comfortable and confident working with trauma survivors in practice. All 92 second-year students participated in the module, and all participated in the post-session assessment.

The first question asked students to provide a list of unanswered questions they had. Questions asked by at least $10 \%$ of the students are listed in Table 1. Many of the questions were related to mandated reporting. In addition, some students wanted to know what types of communication would be professionally appropriate and what questions would be considered too personal.

The second question asked how much more depth the students wanted on TIC and what topics they would like to see covered in future sessions (Table 1). Some students requested more information on what level of injury was required for mandated reporting, and others expressed a hope to become more familiar with appropriate ways to write a chart note in suspected abuse cases. Some requested more information on how to communicate with traumatized individuals, particularly victims of domestic violence. A few also suggested that future sessions could include more role-plays and videos demonstrating appropriate communication with trauma survivors. After the session, two students voluntarily shared with us that they were survivors of traumatic events (e.g., childhood sexual abuse, witnessing domestic violence). These students wanted specific suggestions about managing their own feelings in a professional setting, setting appropriate boundaries, and treating traumatized patients sensitively.

The final question asked how students would prefer to learn this type of material (Table 1). This question was worded as follows: "In future educational offerings, what would help you learn more about this topic? Some examples include a survivor panel, interacting with standardized patients, or completing online tutorials." Some students responded that a guest panel of trauma survivors would be helpful to learn more about how traumatic events influence health, particularly oral health. Others responded that role-playing with other students would help them feel more confident in communicating with trauma survivors. Some students reiterated their desire to become familiar with how to appropriately document suspected abuse situations in a clinical chart. A few also expressed the desire to work with standardized patients to help them with communication skills in this area, as well as requesting access to educational information (e.g., PowerPoint slides) both before and after the sessions to help them prepare ahead of time and give them an opportunity to practice the material they learned at a later date. ${ }^{26}$

\section{Revised Module}

Based on the results of the needs assessment, we modified both the structure and content of our module for the next cohort of second-year dental students $(\mathrm{N}=102)$. The module was expanded to two sessions, and each session was 3.5 hours. This 
Table 1. Students' responses on needs assessment following initial module on trauma-informed care, by percentage of total respondents $(\mathrm{N}=92)$

Question

Percentage

Question 1: what questions do you have after today's presentation?

Mandated Reporting

As a health care professional, what am I obligated to do if I suspect or have secure knowledge that one of my patients is a victim of domestic violence?

What is the exact process for filing a report?

If I believe that a minor is a victim of abuse and the parents are responsible, am I obligated to inform the parents or guardians that I must report them to children and family services?

Will I be penalized if I suspect abuse but do not report it and the abuse ends in injury or death? Will I be penalized if I report abuse and the accusations are proven to be false?

Communication with Traumatized Patients

What is the appropriate language for approaching a patient who is suspected to be a victim of abuse, particularly when approaching minors or the elderly?

How much can I discuss with a patient about an abuse history and still be acting within my professional competence?

Assessment

How do I determine if abuse is severe enough to report?

$18 \%$

$10 \%$

$15 \%$

$13 \%$

$10 \%$

$12 \%$

Question 2: what topics should be covered in future sessions?

Mandated Reporting

More specific information on when and how to report domestic abuse to authorities (for generic scenarios/possibly show example of actual paperwork)?

More information on understanding what level of physical injury needs to be reported.

$15 \%$

$14 \%$

Communication with Traumatized Patients

Techniques on approaching and interviewing suspected victims of domestic violence.

Provide more videos of interviews with victims and experienced professionals.

More student role-plays (interviewing an abuse victim).

Question 3: what educational methodologies should future sessions include?

A guest panel of trauma survivors discussing their experiences in abusive situations and their interactions with medical professionals.

Role-playing with other students or participants to target potential interactions with specific victims/abuse situations (includes filling out "practice" forms for charting in suspected abuse situations, to be evaluated

later for accuracy/appropriateness).

Interacting with standardized patients.

An online tutorial of the seminar's material posted online afterward for an affirmed understanding of content/basic concepts that were presented.

Post an outline of the lecture, activities, or included media (pictures/videos) online ahead of time so participants can prepare themselves before class. information was made available to students one week prior to the session. In addition to the educational content of the original module, the revised module included the following topics: understanding mandated reporting using a detailed handout addressing common student questions; using specific behavioral and communication skills to help minimize anxiety in all patients and the particular importance of these techniques in establishing rapport with traumatized patients; collaborating interprofessionally to effectively treat survivors of traumatic events; developing an awareness of how personal trauma history or other life experiences may influence a clinician's own ability to interact effectively with trauma survivors; screening for traumatic events (e.g., in the case of acute orofacial injury or obvious unexplained bruises on the body); phrasing screening questions; and appropriate reactions when patients disclose trauma histories. This didactic framework, called the Trauma-Informed Pyramid, is fully described elsewhere. ${ }^{1}$

On the first day of the module, we also added two interactive activities. Because we were unable to invite a panel of traumatized patients for logistical reasons, we reviewed videos of actual clinic patients discussing how experiencing traumatic events (e.g., 
domestic violence, childhood sexual abuse, violent crime) had affected their lives and health behaviors. Students were then instructed to role-play in groups of four. These role-plays focused on a patient who was extremely anxious at a dental appointment. The student who was playing the role of the patient was instructed that he or she had a history of some type of traumatic event but did not want to disclose it to the dentist. The scenario gave students the opportunity to practice empathic communication skills. The two students in each group who were not assigned to a character role were given a structured, behaviorally anchored checklist to provide their peers with feedback. They evaluated what they perceived as successful communication strategies (e.g., giving the patient options) and areas for improvement (e.g., no use of open-ended questions, no assessment of patient anxiety). We then debriefed this scenario as a larger group.

The second session of the module contained several additional interactive exercises to allow students to apply the concepts they had learned a week earlier. Based on the students' desire to explore actual cases and get practice with documentation, we included two clinical cases. One case involved possible childhood sexual abuse (as manifested by a wart on the child's palate), and the other involved child neglect (as manifested by a father who came to the dental appointment while inebriated, wanting to drive his son home). Students were instructed to break into small groups of three or four each and write a clinical note (as a team) to document the experience in the patient's record based on how they felt each situation should be handled. We then discussed how each group decided to manage the situation and how they documented each situation in the patient's record. Afterward, students were presented with a sample clinical note, and class discussion focused on the key elements each note should have included.

A standardized patient (a trained medical actor) then role-played in front of the entire class a woman who was the victim of domestic violence. Students volunteered (one at a time) to assume the role of the student dentist as if he or she was treating the standardized patient. The patient, who presented with a loose tooth and bruising on her arms, was hesitant to discuss her abuse with her dentist even when asked directly about the nature of her injuries. The standardized patient was instructed to disclose the abuse if the dentist approached her in a non-judgmental, empathic manner. Students were able to "freeze the action" if they felt unsure of how to proceed in the interaction and seek input from their peers on potential communication. This exercise helped the students gain appreciation for how much depth is professionally appropriate when working with a traumatized patient and how to phrase questions sensitively.

The effectiveness of this revised module was assessed in several ways. A brief, anonymous pre and post multiple-choice test about trauma-related knowledge was administered to the students. We used several pre and post questions to ask students about their comfort and confidence in working with survivors of trauma in a dental setting. Although the chart notes that students wrote with their small groups during the session were used as a method of formative assessment, we also examined them to understand student strengths and weaknesses in abuse-related charting. The students were also asked questions that were similar to the original needs assessment to examine how we might continue to refine this module in the future.

Table 2 provides a summary of student responses pre and post participation in the trauma-informed care module. The module significantly improved students' understanding about how traumatic events are related to health-related coping (e.g., smoking, overeating). Most students had a good understanding of the role of alcohol use prior to the module, so the module did not improve understanding of this issue. However, the module significantly improved students' abilities to identify appropriate and specific communication strategies that could be used when a patient discloses a trauma history; identify the importance of interprofessional collaboration when treating traumatized patients; and identify statements that are not consistent with trauma-informed care (e.g., telling a victim to leave an abuser immediately, telling a victim how to handle the situation).

The students' clinical notes on record documentation were graded to assess their understanding of how a mandated reporting situation should be handled and the components of proper documentation. In the first case (possible child sexual abuse), we wanted to observe if the students referred the child for a biopsy of the wart examined on the palette and if they initiated contact with the child's pediatrician. Students worked in small groups (three or four students per group) to write chart notes. Of the 24 groups, only 14 correctly documented a referral for biopsy and said they would consult with the child's pediatrician. The second case involved possible child neglect, with an inebriated father wanting to drive a child home from a dental appointment. In 
the scenario, when questioned separately, the child reported that the parent often drank alcohol while driving. The chart notes were examined to see if students discussed the situation with the parent, did not allow the child to leave with the intoxicated parent, and planned to report the situation to children and family services. Of the 24 groups, only eight said correctly they would address the issue with the parent, keep the patient in the clinic (not allowing the parent to drive the child home), and report the matter to children and family services.

Table 3 provides an overview of students' selfreported confidence in delivering trauma-informed care before and after the module. These questions were answered anonymously to encourage honest feedback. Response options ranged from $1=$ not at all confident/strongly disagree to $7=$ very confident/ strongly agree. Based on the means, students did report a slight increase in their confidence to communicate sensitively with traumatized patients, both in an acute emergency and in long-term care, and this increase was statistically significant. Although students reported a significantly greater level of understanding of the mandated reporting requirements involved in child abuse and elder abuse, their overall level of confidence remained low, even after

Table 2. Students who correctly answered true-false questions about trauma-informed care before and after participating in revised module, by percentage of total $(\mathrm{N}=102)$

$\begin{array}{lcc}\text { Item } & \text { Before } & \text { After } \\ \text { Module } & \text { Module } & \text { Pearson's } \chi^{2}\end{array}$

What are common ways that people who have survived traumatic events cope later in life?

- Overeating

- Smoking

- Alcohol use

$\begin{array}{llc}66 \% & 90 \% & \chi^{2}=20.87, \mathrm{p}<0.01 \\ 70 \% & 86 \% & \chi^{2}=8.24, \mathrm{p}<0.01 \\ 88 \% & 89 \% & \chi^{2}=0.049, \text { n.s. } \\ & & \\ 40 \% & 70 \% & \chi^{2}=17.82, \mathrm{p}<0.01 \\ 86 \% & 95 \% & \chi^{2}=4.70, \mathrm{p}<0.05 \\ 52 \% & 80 \% & \chi^{2}=18.41, \mathrm{p}<0.01\end{array}$

What is an appropriate way to practice trauma-informed care with a patient?

- Learn to say, "I am not an expert on this, but I have colleagues in various fields I can refer you to."

- Encourage reporting through statements like "This is such a huge problem. I hope you decide to report this and put this guy in jail."*

- Encourage the patient to leave the abuser immediately.*

$52 \%$

$80 \%$

$\chi^{2}=18.41, \mathrm{p}<0.01$

*Correct answer is "false" (not an appropriate trauma-informed care response). For other items, "true" is the correct response.

Table 3. Students' confidence and understanding of trauma before and after participating in revised module, by mean (standard deviation) of total $(\mathrm{N}=102)$

$\begin{array}{ccc}\text { Item } & \text { Before } & \text { After } \\ \text { Module } & \text { Module }\end{array}$

How confident do you feel in your ability to:

- Communicate sensitively with a patient who has a history of traumatic events (childhood sexual abuse, domestic violence, etc.).

- Communicate sensitively with a patient immediately after a traumatic event (e.g., a domestic violence survivor seeking care for orofacial injuries).

I understand when I am mandated to report child abuse.

$3.5(1.04) \quad 4.0(0.86) \quad \mathrm{t}(202)=3.66, \mathrm{p}<0.01$

$3.4(1.07) \quad 4.0(0.83) \quad \mathrm{t}(202)=3.70, \mathrm{p}<0.01$

I understand when I am mandated to report elder abuse.

$4.2(1.06)$

$4.7(0.60)$

$\mathrm{t}(202)=3.86, \mathrm{p}<0.01$

I understand when I am mandated to report domestic violence.

$4.2(0.94)$

$4.6(0.76)$

$\mathrm{t}(202)=3.33, \mathrm{p}<0.01$

I worry that I might upset my patients if I ask them about their

$4.0(0.95)$

$4.0(1.27)$

$\mathrm{t}(202)=0.32$, n.s.

$3.3(1.00)$

$3.3(1.10)$

$\mathrm{t}(202)=0.28$, n.s. personal stressors.

$3.0(1.11) \quad 3.9(0.84) \quad \mathrm{t}(202)=6.03, \mathrm{p}<0.01$

I feel well trained to treat survivors of traumatic events in my practice.

Note: Response options ranged from $1=$ not at all confident/strongly disagree to $7=$ very confident/strongly agree. 
module completion. After module completion, the means also showed that students remained unsure about when to report domestic violence (which does not mandate report in the state of our dental school). Module completion did not appear to help students overcome their worries about upsetting patients when asking about personal stressors.

Similar to the initial needs assessment, after the revised module was completed, we asked students to write down the remaining questions they had related to the topic of trauma. Table 4 shows questions asked by at least $10 \%$ of the students. As opposed to the initial needs assessment, most of the questions were not focused on the technicalities of mandated reporting. Instead, many students had questions about the nuances of communicating with traumatized patients, including how much personal information they should solicit and how to recognize if they were being professionally appropriate in these discussions.

We also asked students what future educational methods would help them to feel comfortable and confident in working with survivors of traumatic events. Table 5 reports suggestions given by at least $10 \%$ of the students. Among the suggestions were subsequent sessions to include more work with standardized patients, question and answer sessions with a survivor panel, an online tutorial with video, and more practice documenting real scenarios. In addition, some students requested a follow-up session after they had more clinical experience working with traumatized patients.

\section{Future Directions}

The revised interactive module "Trauma-Informed Care for Dental Students" that we created was effective in increasing student knowledge in certain areas, such as potential health-related consequences of traumatic events. The module also helped to slightly increase students' confidence in their ability to effectively treat survivors of trauma in their practice. Based on pre- and post-module student responses, this interactive module improved learning outcomes to a greater extent than the traditional single session lecture used previously. Although students began the revised module as neutral or somewhat confident in treating survivors of trauma, their confidence was belied by their inability to appropriately document abuse and by their lack of initial knowledge. Our findings are similar to those of Connor et al. ${ }^{16}$ who found that dental students' level of perceived preparation to interact with survivors of interpersonal violence does not accurately predict knowledge in the area of interpersonal violence. It is also probable that after students completed the interactive exercises in the module, they better understood how challenging the communication and legal aspects of these encounters can be. In our original module, student questions afterwards focused on the technicalities of mandated reporting. In our revised module, student questions afterwards focused more on the communication and documentation nuances involved in TIC, indicating a deeper understanding of the complexity of the tasks.

Table 4. Students' questions remaining after participating in revised module, by percentage of total $(\mathrm{N}=102)$

\begin{tabular}{ll} 
Question & Percentage \\
\hline Do you have to report the abuse of any child or just the abuse of children who are directly under your clinical care? & $10 \%$ \\
How much can you ask about personal matters? How much detail do you ask at follow-up appointments when & $13 \%$ \\
patients have disclosed abuse? How can you phrase questions about abuse and trauma? &
\end{tabular}

Table 5. Students' suggestions for other educational methods to be added to revised module, by percentage of total $(\mathrm{N}=102)$

Educational Method

Percentage

Role-play

Standardized patients (especially types of patients with whom one doesn't normally come into contact)

$47 \%$

Survivor panel

Online tutorial/videos (to understand how to work with survivors)

$21 \%$

Documentation of real scenarios (PowerPoint format) and their results/debriefing scenarios

$15 \%$

Follow-up session after actual patient encounters

$13 \%$

$10 \%$ 
Students generally reported that they wanted more interaction with standardized patients and survivor panels and more documentation practice, and they suggested online tutorials and follow-up sessions. This indicates that, in order to accomplish the goals of TIC, multiple sessions are required. Ivanoff and Hottel laid out a comprehensive training strategy for teaching dental students about child abuse and neglect. ${ }^{27}$ They suggested that sessions take place over several years and include case-based learning with students in early dental education and, in subsequent years, follow-up with interprofessional case-based learning (dental, medical, and nursing students) and standardized patient interactions. The results of our student feedback also suggest high-fidelity, interactive experiences are essential in helping students understand trauma-informed care. Our revised module contained activities to help students gain practice with these skills, including role-plays, discussion of patient video vignettes, practice writing mock clinical notes, and interaction with a standardized patient. We believe that future educational endeavors in this area can be improved by following student suggestions, giving students access to a survivor panel, and providing computerized TIC tutorials and follow-up sessions throughout their dental education. Overall, we found that collecting student questions and feedback was a powerful way to refine educational modules, particularly as it relates to difficult behavioral skills.

\section{Conclusion}

Engaging traumatized patients in oral health care is an important priority. Traumatized patients may present in oral health settings for acute injury and routine dental care. In the long term, they may suffer from dental anxiety and negative ways of coping that influence their oral health. Helping dentists deliver trauma-informed care may help individual patients feel more at ease, increase engagement in regular preventive care, and positively affect oral health care at a national level. It is critical that future educational efforts continue to focus on training dental professionals who are prepared to provide patient-centered trauma-informed care.

\section{REFERENCES}

1. Raja S, Hoersch M, Rajagopalan CF, Chang P. Treating patients with traumatic life experiences: providing traumainformed care. J Am Dent Assoc 2014;145(3):238-45.
2. American Dental Association. Principles of ethics and code of professional conduct. At: www.ada.org/sections/ about/pdfs/code_of_ethics_2012.pdf. Accessed: 11 June 2013.

3. Gironda WM, Lefever KH, Anderson EA. Dental students' knowledge about elder abuse and neglect and the reporting responsibilities of dentists. J Dent Educ 2010;74(8):824-9.

4. Jordan A, Welbury RR, Tiljak MK, Cukovic-Bagic I. Croatian dental students' educational experiences and knowledge in regard to child abuse and neglect. J Dent Educ 2012;76(11):1512-9.

5. Murphree KR, Campbell PR, Gutmann ME, et al. How well prepared are Texas dental hygienists to recognize and report elderly abuse? J Dent Educ 2002;66(11):1274-80.

6. Al-Jundi SH, Zawaideh FI, Al-Rawi MH. Jordanian dental students' knowledge and attitudes in regard to child physical abuse. J Dent Educ 2010;74(10):1159-65.

7. Sugita JA, Garrett MD. Elder abuse and oral health care providers: an intervention to increase knowledge and self-perceived likelihood to report. J Elder Abuse Negl 2012;24(1):50-64.

8. Thomas JE, Straffon L, Inglehart MR. Knowledge and professional experiences concerning child abuse: an analysis of provider and student responses. Pediatr Dent 2006;28(5):438-44.

9. Ko SJ, Ford JD, Kassam-Adams N, et al. Creating trauma-informed systems: child welfare, education, first responders, health care, juvenile justice. Prof Psychol 2008;39(4):396-404.

10. Substance Abuse and Mental Health Services Administration. SAMHSA trauma-informed care and trauma services. At: www.samhsa.gov/nctic/trauma.asp. Accessed: 11 June 2013.

11. Harris M, Fallot RD. Using trauma theory to design service systems. San Francisco: Jossey-Bass, 2001.

12. Raja S, Hoersch M. Trauma-informed care: how can medical and dental providers effectively work with survivors of traumatic events. Ann Behav Med 2012(Suppl 1):S4.

13. Nelms AP, Gutmann ME, Solomon ES, et al. What victims of domestic violence need from the dental profession. $\mathrm{J}$ Dent Educ 2009;73(4):490-8.

14. Love C, Gerbert B, Caspers N, et al. Dentists' attitudes and behaviors regarding domestic violence: the need for an effective response. J Am Dent Assoc 2001;132(1):85-93.

15. Everett RJ, Kingsley K, Demopoulos CA, et al. Awareness and beliefs regarding intimate partner violence among first-year dental students. J Dent Educ 2013;77(3):316-22.

16. Connor PD, Nouer SS, Mackey SN, et al. Dental students and intimate partner violence: measuring knowledge and experience to institute curricular change. J Dent Educ 2011;75(8):1010-9.

17. Banyard V, Potter S, Turner H. The impact of interpersonal violence in adulthood on women's job satisfaction and productivity: the mediating roles of mental and physical health. Psychol Violence 2011;1(1):16-28.

18. Irish L, Kobayashi I, Delahanty DL. Long-term physical health consequences of childhood sexual abuse: a metaanalytic review. J Pediatr Psychol 2010;35(5):450-61.

19. Eisen SV, Schultz MR, Vogt D, et al. Mental and physical health status and alcohol and drug use following return deployment to Iraq or Afghanistan. Am J Public Health 2012;102(Suppl 1):S66-73. 
20. Banyard VL, Edwards VJ, Kendall-Tackett K. Trauma and physical health: understanding the effects of extreme stress and of psychological harm. Abingdon: Routledge, 2009.

21. Breiding MJ, Black MC, Ryan GW. Prevalence and risk factors of intimate partner violence in eighteen U.S. states/ territories, 2005. Am J Prev Med 2008;34(2):112-8.

22. Felitti VJ, Anda RF, Nordenberg D, et al. Relationship of childhood abuse and household dysfunction to many of the leading causes of death in adults: the adverse childhood experiences (ACE) study. Am J Prev Med 1998;14(4): 245-58.

23. Hollister MC, Anema MG. Health behavior models and oral health: a review. J Dent Hyg 2004;78(3):6.
24. Stalker CA, Russell BD, Teram E, Schachter CL. Providing dental care to survivors of childhood sexual abuse: treatment considerations for the practitioner. J Am Dent Assoc 2005;136(9):1277-81.

25. Oosterink FM, de Jongh A, Aartman IH. What are people afraid of during dental treatment? Anxiety-provoking capacity of 67 stimuli characteristic of the dental setting. Eur J Oral Sci 2008;116(1):44-51.

26. Parolia A, Mohan M, Kundabala M, Shenoy R. Indian dental students' preferences regarding lecture courses. J Dent Educ 2012;76(3):366-71.

27. Ivanoff CS, Hottel TL. Comprehensive training in suspected child abuse and neglect for dental students: a hybrid curriculum. J Dent Educ 2013;77(6):695-705. 